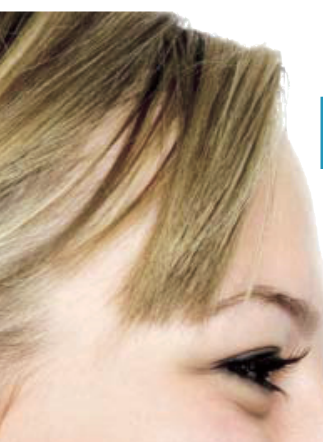

Wer hat das feinere Näschen?

Bi ei einem Geruchstest am Monell Chemical Senses Center in Philadelphia, USA, schnupperten Frauen und Männer zunächst an Achselschweißproben. Dabei erschien der Geruch beiden Geschlechter gleich stark. Doch sobald die Forscher angenehme Duftstoffe dazu mischten, nahmen Frauen und Männer die Gerüche unterschiedlich wahr: In den Nasen der Frauen übertönten nur zwei von 32 Duftnoten den Achselgeruch erfolgreich. Dagegen ließen sich die Männer leichter täuschen: Sie fanden, dass 19 Duftnoten den strengen Geruch signifi-

kant unterdrücken konn-

ten. Männlicher Geruch

war zudem grundsätzlich schwieriger zu kaschieren als weiblicher. Der männliche Schweiß enthält vermutlich Informationen für die Partnerwahl, mutmaßt Studienleiter Charles Wysocki, die Frauen mit ihren feineren Näschen aufspüren können.

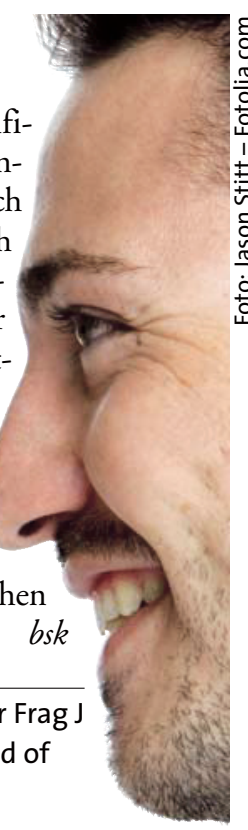

Wysocki CJ et al. Flavour Frag J 2009 Feb 23 [Epub ahead of print]

\section{Juckender Zahnersatz}

obaltchlorid ist das dritthäufigste Kontaktallergen bei Kindern. Das Metallsalz findet sich häufig in zahnärztlichen Materialien, ruft dann aber erstaunlicherweise nur sehr selten eine Kontaktreaktion hervor. Trotzdem sollte an eine solche Allergie gedacht werden. Dies zeigt der Fall eines siebenjährigen Mädchens, das sich mit Juckreiz und Schmerzen an der Zunge vorstellte. Neun Monate zuvor hatte das Kind nach dem Verlust des linken Schneidezahns ein Zahnimplantat erhalten, das mit einer kobalthaltigen Metalllegierung befestigt worden war. Im Patchtest ergab sich eine positive Reaktion auf Kobaltchlorid. Nach Entfernen der kobalthaltigen Halterung des Kunstzahns verschwanden die Symptome an der Zunge.

Waroquier D et al. Contact Dermatitis 2009; 60: 106

\section{Tofu und Sport} Darauf weist eine DNA-Mikroarray-Untersuchung hin, bei der das Genexpressionsprofil von Entzündungszellen aus der brochoalveolären Lavage von Patienten, die auf Glukokortikoide ansprachen, mit dem von Asthmakranken, die resistent gegen Glukokortikoide waren, verglichen wurde. Die Makrophagen der resistenten Patienten zeigten dabei eine

stärkere proinflammatorische und antimikrobielle Aktivierung im Vergleich zu den Makrophagen der sensitiven Patienten. Außerdem fanden sich in der Lavage der therapieresistenten Probanden hohe Lipopolysaccharidspiegel. Eine Assoziation von Lipopolysaccharidexposition mit gesteigerter Asthmainzidenz und -schwere ist bekannt.

$b k$

Goleva E et al. J Allergy Clin Immunol

2008; 122: 550-9

\title{
Die Bockshornklee-Erdnuss-Connection
}

B ockshornklee (Trigonella foenumgraecum) ist eine seit langem genutzte Kulturpflanze aus der Familie der Schmetterlingsblütler. Das Kraut bzw. seine Samen sind eine beliebte Zutat in Curry-Mischungen der indischen Küche. In Europa ist eine Sensibilisierung gegen Bockshornklee keine Seltenheit, wie eine Untersuchung der Seren von 29 Patienten aus Nor-

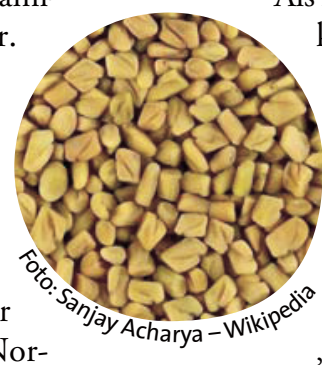

Familie der Schmetterlingsblütler. Hier kommt es offenbar zu Kreuzreaktionen.

Als Majorallergene des Bockshornklees wurden Proteine in den Bereichen 50,52 und $74 \mathrm{kD}$ identifiziert. Nur bei einem Drittel der in der Studie überprüften Nahrungsmittel war Bockshornklee offen deklariert, meistens versteckte er sich unter der Angabe „Gewürze“. $b k$ wegen zeigt. Betroffen sind vor allem Patienten mit einer Primärallergie gegen Erdnuss, eine Pflanze ebenfalls aus der
Kruse Fæste C et al. J Allergy Clin Immunol 2009; 123: 187-94

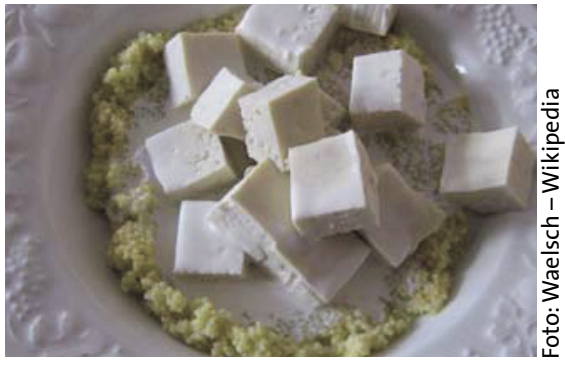

C in außergewöhnlicher Fall einer Nah- rungsmittelallergie wird aus Japan berichtet: Ein 16-jähriges Mädchens zeigte eine anstrengungsinduzierte Anaphylaxie gegen Tofu, nicht aber gegen Sojamilch. Tofu wird durch Ausfällung von Sojamilch überwiegend durch Magnesiumchlorid hergestellt. Durch Immunoblot, ELISA und Protein-Mircoarray-Testung wurde $\beta$-Conglycinin als Auslöser der Allergie identifiziert. Während des Verdauungsvorgangs wird $\beta$-Conglycinin aus Sojamilch vollständig denaturiert, dagegen widersteht $\beta$-Conglycinin aus Tofu der Verdauung und gelangt als unverändertes Protein in den Dünndarm.

Adachi A et al. Clin Exp Allergy 2009; 39: 167-73 